06

\title{
Контролируемый синтез графена на меди с использованием метода имплантации атомов отдачи углерода
}

\author{
() А.Ф. Вяткин \\ Институт проблем технологии микроэлектроники и особочистых материалов РАН, Черноголовка, Московская обл., \\ Россия \\ E-mail: vyatkin@iptm.ru
}

Поступило в Редакцию 23 ноября 2018г.

В окончательной редакции 29 ноября 2018 г.

Принято к публикации 29 ноября 2018г.

Рассматривается метод синтеза графена на поверхности медной фольги с использованием холодной имплантации атомов отдачи углерода. Показано, что при определенных условиях обработки имплантированных углеродом образцов медной фольги (температуре отжига, времени отжига и скорости охлаждения) на поверхности образцов фольги формируются монослойные пленки графена.

DOI: 10.21883/PJTF.2019.04.47339.17604

После демонстрации уникальных электронных свойств графена [1] в научной литературе появилось много работ, посвященных его росту [2]. Независимо от способа синтеза графен в них характеризовался по крайней мере тремя основными параметрами: толщина (количество монослоев), однородность и сплошность на больших площадях, которые определяют практические параметры этого материала (подвижность носителей заряда, механические и оптические свойства) и, следовательно, области его применения. К настоящему времени наиболее продвинутым методом синтеза с точки зрения этих требований является метод химического осаждения из газовой фазы (CVD). Ключевым для этого метода является выбор подложки-катализатора и прекурсора - источника атомов углерода. Как правило, подложкой служит металл-катализатор. Различают два вида металлов для подложек-катализаторов: с высокой растворимостью углерода ( $\mathrm{Ni}, \mathrm{Co}, \mathrm{Pd}, \mathrm{Ru}, \mathrm{Mo}, . .$.$) и$ с низкой растворимостью углерода $(\mathrm{Cu}, \mathrm{Pt}, \mathrm{Ag}, \ldots)$. В первом случае CVD-синтез графена происходит по следующей схеме: поверхностная сегрегация углерода с дальнейшей его преципитацией [3]. Во втором случае, т.е. при малой растворимости углерода в металле, процесс роста регулируется некоторым поверхностным механизмом, который при определенных условиях синтеза является самолимитирующим. Последнее означает, что реализуется только монослойный рост графена. Комбинация двух типов металлических подложек также используется для роста графена [4]. В качестве источника атомов углерода в CVD-процессах наиболее часто применяются метан $\left(\mathrm{CH}_{4}\right)$ [5] и другие ароматические соединения, например $\mathrm{C}_{6} \mathrm{H}_{6}, \mathrm{C}_{18} \mathrm{H}_{14}$ [6].

Отличным от CVD методом введения углерода в подложку-катализатор является имплантация ионов углерода [7]: в процессе CVD источник углерода, как правило, образуется за счет каталитического разложения молекул углеводорода на углерод и водород. Анализ немногочисленных публикаций [8], описывающих проце- дуру роста графена с применением ионной имплантации, показывает как достоинства, так и недостатки этого метода, в частности формирование источника атомов углерода на значительном расстоянии от поверхности подложки, на которой происходит рост графена.

Устранить этот недостаток можно за счет использования разновидности метода ионной имплантации имплантации атомов отдачи [9]. Правильный выбор параметров этого процесса (толщина слоя углеродсодержащего материала, энергия и доза пучка первичных ионов) позволяет сформировать источник атомов углерода в приповерхностной области подложки-катализатора. Таким образом существенно сокращается стадия диффузионного переноса атомов углерода к поверхности подложки-катализатора, на которой происходит синтез графена, т.е. увеличивается скорость роста зерен графена.

В настоящей работе исследуется процесс синтеза графена на меди из источника атомов углерода, образованного за счет холодной имплантации атомов отдачи углерода. В предыдущей публикации [9] было показано, что применение такого способа синтеза графена на никелевой подложке позволяет создавать многослойные графеновые структуры. В работе исследовались образцы медной фольги Компании ГРАНД-МЕТАЛЛ толщиной $25 \mu \mathrm{m}$ и площадью $1-4 \mathrm{~cm}^{2}$. Подготовка образца медной фольги для синтеза графена включала в себя стадию предварительной химической очистки поверхности фольги [10] и отжиг в водороде в течение $30 \mathrm{~min}$ при температуре $1273 \mathrm{~K}$. После этого образец фольги $\left(1 \mathrm{~cm}^{2}\right)$ крепился на охлаждаемом держателе в вакуумной камере ионного имплантера Extrion (Varian 2001000). Дополнительно производилась очистка поверхности медной фольги за счет распыления ионами аргона $\left(E=40 \mathrm{keV}\right.$, доза $\left.2 \cdot 10^{15} \mathrm{~cm}^{-2}\right)$.

Для проведения процесса имплантации атомов отдачи углерода камера имплантера откачивалась до давления $\sim 10^{-4} \mathrm{~Pa}$, затем медный образец охлаждался до темпе- 

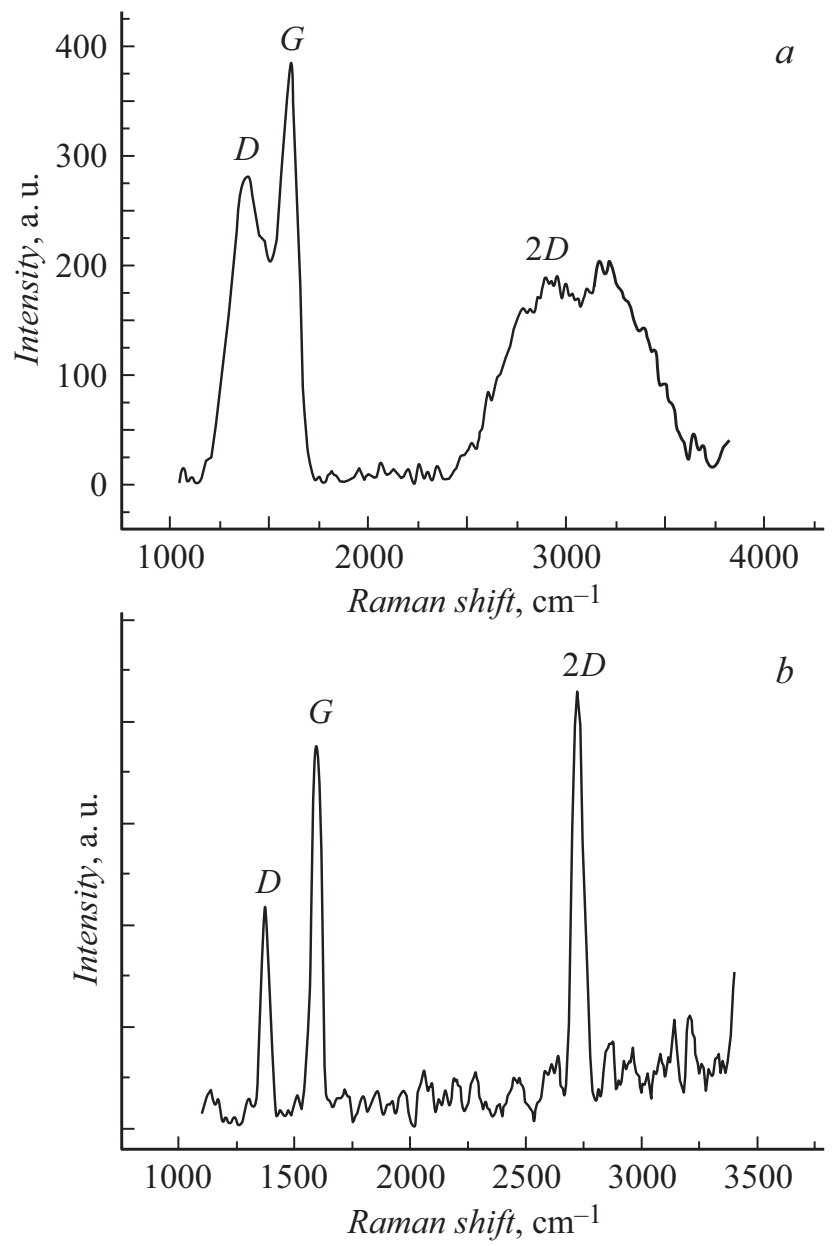

Рис. 1. Спектры комбинационного рассеяния, полученные после отжига при температуре $1223 \mathrm{~K}$ с различными временами отжига и охлаждения: $a-$ быстрое, $b-$ медленное охлаждение.

ратуры $\sim 80 \mathrm{~K}$ с использованием жидкого азота в качестве охладителя. После этого в камеру образцов имплантера напускался ацетилен $\left(\mathrm{C}_{2} \mathrm{H}_{2}\right)$ при парциальном давлении $2.7 \cdot 10^{-4} \mathrm{~Pa}$ в течение $1 \mathrm{~min}$, затем натекание ацетилена уменьшалось до $\sim 1.35 \cdot 10^{-4} \mathrm{~Pa}$. На поверхности медной фольги конденсировалась пленка ацетилена в твердой фазе $\left(T_{m}\right.$ ацетилена $\left.\sim 188 \mathrm{~K}\right)$. При облучении такой системы (пленка $\mathrm{C}_{2} \mathrm{H}_{2}$ на медной фольге) ионами $\mathrm{Ar}^{+}$(энергия $40 \mathrm{keV}$, плотность тока пучка $1 \mu \mathrm{A} / \mathrm{cm}^{2}$ и доза $2.5 \cdot 10^{14} \mathrm{~cm}^{-2}$ ) происходило внедрение атомов углерода в медную фольгу за счет явления имплантации атомов отдачи. Методами вторичной ионной массспектрометрии было определено [9], что атомы отдачи углерода сосредоточены в узком приповерхностном слое медной фольги толщиной 10-15 nm. После облучения ионами аргона образцы медной фольги отжигались в вакууме при температурах $873-1273 \mathrm{~K}$ при различных временах отжига и скоростях охлаждения. Число технологических процессов, используемых в данном методе синтеза графена, не превышает их числа в методе CVD, а трудоемкость наиболее сложных процессов (имплантация атомов отдачи + отжиг в первом и каталитическое осаждение с последующим отжигом во втором) для обоих методов близка.

Для характеризации поверхности образцов после отжига использовалась спектроскопия комбинационного рассеяния. Спектры измерялись в 8-10 разных точках на поверхности образцов с помощью рамановского микроскопа SENTERRA Bruker с длиной волны лазера $488 \mathrm{~nm}$. Диаметр лазерного пучка составлял величину порядка $1 \mu \mathrm{m}$. У образцов, отожженных при температурах $873-1173 \mathrm{~K}$, в спектрах комбинационного рассеяния отсутствуют пики, характерные для графена. Только при температурах отжига $1223-1323 \mathrm{~K}$ в спектрах появляются пики $D, G$ и $2 D$, присущие графену [11]. На рис. $1, a$ приведен спектр комбинационного рассеяния, полученный для образца имплантированной фольги, отожженного при температуре $1223 \mathrm{~K}$ в течение 7 min и быстро охлажденного до комнатной температуры (скорость охлаждения $\sim 300 \mathrm{~K} / \mathrm{min}$ ). На спектре виден широкий пик в области $3000 \mathrm{~cm}^{-1}$, свидетельствующий о наличии многослойной графеноподобной структуры на поверхности медной фольги. Высокая интенсивность пика $D$ в области $\sim 1380 \mathrm{~cm}^{-1}$ указывает на большую дефектность полученной структуры. Увеличение времени отжига до $30 \mathrm{~min}$ и медленное охлаждение образца $(\sim 30 \mathrm{~K} / \mathrm{min})$ приводит к существенному изменению спектра комбинационного рассеяния (рис. 1,b). Пик $2 D$ стал значительно у́же (полуширина на полувысоте $45.3 \mathrm{~cm}^{-1}$ ), уменьшилась и интенсивность пика $D$, характеризующего дефектность пленки графена. В исследованиях свойств графена методом комбинационного рассеяния удобным параметром оценки количества монослоев является отношение интенсивностей пиков $I_{2 D} / I_{G}$. Когда это отношение больше единицы, количество монослоев графена меньше четырех [12]. Таким образом, исходя из

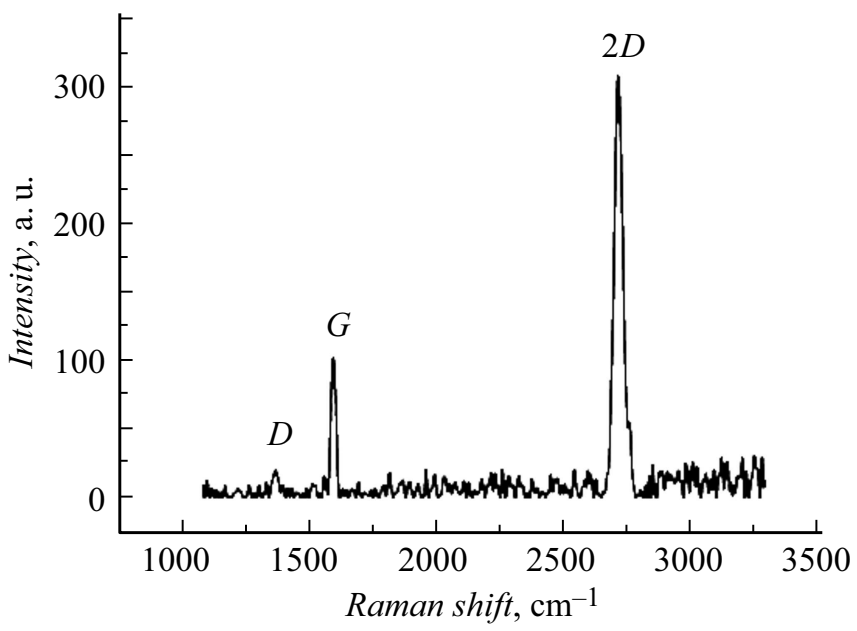

Рис. 2. Типичный спектр комбинационного рассеяния, полученный для имплантированного образца, отожженного при температуре $1273 \mathrm{~K}$ в течение $30 \mathrm{~min}$ и медленно охлажденного $(30 \mathrm{~K} / \mathrm{min})$ до комнатной температуры. 
спектра на рис. 1, $b$ можно сделать вывод, что при указанных режимах отжига на поверхности медной фольги формируется пленка графена с большой дефектностью и количеством монослоев, равным $\sim 4$.

На рис. 2 показан типичный спектр комбинационного рассеяния, характерный для монослойного графена. В спектре едва заметен пик $D$. Малая интенсивность пика $D$ указывает на малое количество дефектов в графене. Ширина на полувысоте пика $G\left(16.7 \mathrm{~cm}^{-1}\right)$ свидетельствует о высокоупорядоченной гексагональной структуре атомов углерода. Отношение интенсивностей $I_{2 D} / I_{G}=3$ подтверждает, что пленка графена монослойная (в литературе принято считать, что если $I_{2 D} / I_{G}>2$, то пленка графена состоит из одного монослоя).

Полученные экспериментальные данные свидетельствуют о формировании монослойных структур графена, образующихся в результате синтеза графена на медных подложках, созданных методом холодной ионной имплантации атомов отдачи углерода, которые характеризуются высоким качеством кристаллической структуры. Однако независимо от способа роста пленки графена структурное совершенство ее при переносе на другие подложки ухудшается за счет внесения в нее в процессе переноса кристаллических дефектов и механических напряжений.

Показано, что определяющими параметрами формирования монослойной пленки графена являются высокая температура отжига и медленная скорость охлаждения образца. При этом наиболее оптимален для получения монослойного графена отжиг имплантированного образца при температурах, близких к температуре плавления меди, в течение $30 \mathrm{~min}$ с последующим медленным охлаждением $(\sim 30 \mathrm{~K} / \mathrm{min})$ до комнатной температуры.

Автор выражает благодарность В.И. Зиненко, Ю.А. Агафонову и О.В. Кононенко за существенную помощь в проведении экспериментов и за плодотворное обсуждение результатов.

Работа выполнена при финансовой поддержке Программы фундаментальных исследований Президиума РАН „Наноструктуры: физика, химия, биология, основы технологий“ в рамках научного направления „Композиционные материалы на основе наноразмерных форм углерода“, проект „Графен и материалы на его основе“.

\section{Список литературы}

[1] Novoselov K.S., Geim A.K., Morozov S.V., Jiang D., Zhang Y., Dubonos S.V., Grigorieva I.V., Firsov A.A. // Science. 2004. V. 306. N 5696. P. 666-669.

[2] Антонова И.В. // УФН. 2013. Т. 183. N 10. С. 1115-1122.

[3] Kim K.S., Zhao Y., Jang H., Lee S.Y., Kim J.M., Kim K.S., Ahn J.H., Kim P., Choi J.Y., Hong B.H. // Nature. 2009. V. 457. N 7230. P. 706-710.

[4] Luo B., Caridad J.M., Whelan P.R., Thomsen J.D., Mackenzie D.M.A., Grubišić-Čabo A., Mahatha S.K, Bianchi M., Hofmann P., Jepsen P.U., Bøoggild P., Booth T. // 2D Mater. 2017. V. 4. N 4. P. 045017.
[5] Reina A., Jia X., Ho J., Nezich D., Son H., Bulovic V., Dresselhaus M.S., Kong J. // Nano Lett. 2008. V. 9. N 1. P. 30-35.

[6] Lee H.C., Liu W.-W., Chai S.P., Mohamed A.R., Lai C.W., Khe C.S., Voon C.H., Hashim U., Hidayah N.M.S. // Procedia Chem. 2016. V. 19. P. 916-921.

[7] Wang G., Zhang M., Liu S., Xie X., Ding G., Wang Y., Chu P.K., Gao H., Ren W., Yuan Q., Zhang P., Wang X., Di Z. // Adv. Funct. Mater. 2015. V. 25. N 24. P. 3666-3675. https://doi.org/10.1002/adfm.201500981

[8] Lee J.S., Jang C.W., Kim J.M., Shin D.H., Kim S., Choi S.-H., Belay K., Elliman R.G. // Carbon. 2014. V. 66. P. 267-271.

[9] Агафонов Ю.А., Зиненко В.И., Кононенко О.В., Сарайкин В.В. // Письма в ЖТФ. 2017. Т. 43. В. 12. С. 52-58.

[10] Kim S.M., Hsu A., Lee Y.-H., Dresselhaus M., Palacios T., Kim K.K., Kong J. // Nanotechnology. 2013. V. 24. N 36. P. 365602.

[11] Shams S.S., Zhang R., Zhu J. // Mater. Sci.-Poland. 2015. V. 33. N 3. P. 566-578. DOI: $10.1515 / / \mathrm{msp}-2015-0079$

[12] Yu Q.K., Lian J., Siriponglert S., Li H., Chen Y.P., Pei S.S. // Appl. Phys. Lett. 2008. V. 93. N 11. P. 113103 (1-3). 